\title{
Los procesos de modernización y cientificación como forma de agresión a la biodiversidad sociocultural ${ }^{1}$
}

\author{
Eduardo Sevilla Guzmán ${ }^{*}$ y Graciela Ottmann ${ }^{* *}$
}

\section{Nota introductoria}

El presente trabajo es una reflexión, desde la agroecología, respecto al surgimicnto de la ciencia y al concepto de naturaleza que eila genera, donde el hombre aparece como un elemento difcrenciado y capaz de dominarla. El mercado es incorporado por la cpistemología científica, a través del liberalismo histórico, como un referente ético que establece la justicia social, produciendo una ruptura con el manejo sustentable de los recursos naturajes históricamente desarrollados por los pueblos indígenas. Aparece así, dentro del pensamiento científico, la "modernidad" como camino único a seguir y el mancjo industrial de los recursos naturales como la vía "moderna y supcrior" que ineluctablemente ha de sustituir al uso múltipic del territorio desarrollado por los campesinos.

Frente a la cientificación del hombre y la naturaleza, que imprime un deterioro a los recursos naturales y a la sociedad, la agroecología introduce la emergente ética ecológica necesaria de incorporar a la sustentabilidad para enfrentarse al discurso ecotecnocrático de la sostenibilidad construido desde el neoliberalismo medioambiental.

Lo que intentamos en el presente artículo es definir la «ciencia» en su contexto social, político, histórico y cultural, esto es, como un producto social que excluye a los grupos indígenas, mostrando así cómo la ciencia legitima el ecocidio cultural en pos de la modernidad.

\author{
Sobre el surgimiento de la ciencia: el medio \\ ambiente como pecado original de la Ilustración
}

Cuando Karl Marx afirmara que "la agricultura es el pecado original que introduce la riqueza en el mundo"2 expresaba, con una extraordinaria capacidad de síntesis, la concepción ilustrada de los recursos naturales. Como los fisiócratas, Marx pensaba que, desde el punto de vista de la génesis de riqueza, la agricultura $^{3}$ era el motor de la creación de riqueza posterior. ${ }^{4}$

La introducción de la actividad industrial y mercantil como nuevas formas de creación de "valores de uso" son solamente posibles cuando a partir del desarrollo dc la agricultura sc logra crear un excedentc agrícola suficiente para liberar una parte de la mano de obra e introducir así una mayor división del trabajo social. Se inicia de esta forma "la ineluctable" industrialización de la agricultura proclamada tanto por el marxismo ortodoxo como por el pensamiento liberal.

A partir de los años ochenta diversos estudiosos economistas, sociólogos, agrónomos y antropólogos han demostrado, utilizando una perspectiva ecológica, cómo, tanto la economía marxista como la economía liberal, mancjan unos conceptos (capital, inversión, contabilidad nacional, entre otros) que entran en clara colisión con los principios de las ciencias naturales (la Segunda ley de la Termodinámica o del principio de intercambio abierto de la ecología general). Pero además, los esqucrnas teóricos de la economía convencional dejan en manos de un mecanismo socialmente construido pero que se postula naturai, el mercado, la regulación y el control de los mecanismos de la reproducción biótica y social. ${ }^{5}$ La historia, saleza: pecado original éste que introduce en la ciencia los mecanismos de degradación de los recursos naturales.

1 Ponencla presentada en la Conterencia Internacional "Estilos ce desarrolio en América Latina: Propositos y olvidos", co-organizada por el CES de la UCT, en Julio de 1988.

(7) Instituto de Sociologle y Estudios Campesinos (ISEC), Univers/dad de Cordobe, Españ.

(7) Facultad de Clancias Veterinarias, Universidad Nacionat de Rosario, Argentina.

2 MARX, K., Le Cabital, Primera versión francesa traducida por Joseph Fay revisada por Marx. Editions Sociales, Paris, 1950. Liuro I, tamo de ia $2^{\bullet}$ edición alemana y Hi: p. 154.

3 Más concrotamente la actividad agrarla ye que Max conslderaba el trabaja como única fuente de creación do rlqueza Ct. Su teoria del valor, Lituro I, Sección $1 \bullet$. En fa varglón casteliana de Pedro Scaron traducida de la segunda ediclón alemana. El Capltal Tarno :. Vol. I. Libro primero. El proceso de produeción del capltal. Siglo XXI, Madrid, 1996, 21ed. pp.43-102.

4 CI. MARX, K, op,cit, "La acumulacion primitiva", sección VII del lioro It tomo :II. Ed, Cast. Pp.891-954.

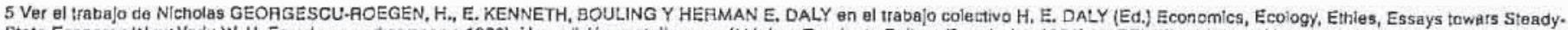

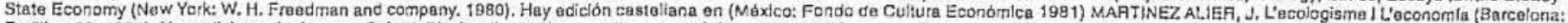
Ecdition 62: 1984). Hay ediclones inglesa en Oxtord; Blackewl!, 1990) y castellana en México: FCE. 1991). 


\section{El hombre como construcción cultural ilustrada}

La Iustración fue el movimiento cultural europeo que pretendía disipar las tinicblas de la humanidad mediante las luces de la razón. Temporalmente coincide, en una primera aproximación, con el periodo de cien años que va desce la publicación de An Essay' conceming human understanding de John Locke en 1690 hasta la Revolución francesa. Es entonces cuando se establecen los cimientos del pensamiento científico moderno. El siglo XVIC es el periodo en que los "filósofos sociales sacaron por primera vez a la luz las cuestiones centrales de las ciencias sociales contemporáneas esforzándose, aunque sin éxito, en formular las leyes que gobiernan el curso de la historia humana y la evolución de las diferencias y similitudes socioculturales. Las ciencias sociales siguieron a Locke en su convencimiento de que a pesar de sus diferencias de experiencia, la razón correctamente aplicada podría llevar al hombre a las mismas verdades técnicas y científicas. ${ }^{6}$ Copérnico, Kepler y Galileo son junto a Descartes los forjadores de la "nueva ciencia" quc genera la modernidad y el racionalismo. Durante la Ilustración se continúa el legado de Francis Bacon respecto al dominio del hombre sobre la Naturaleza a través de la ciencia, lo que permitiría "unir sus fuerzas contra la Naturaleza de las cosas, atacar y ocupar sus castillos y reductos, y extender los límites del imperio humano tan lejos como Dios Todopoderoso lo permita".

La Ilustración construye una "cosmovisión" en la que se genera el conocimiento científico como resultado de "los progresos sucesivos de la humanidad" en los que "los primeros principios del hombre", por un lado, y "el desarrollo del lenguaje, de la moralidad, de las costumbres, de las artes y las ciencias", por otro, pueden ser "abarcados por la educación" como elemento mitigador de las diferencias que la naturaleza establece entre los hombres construyéndose así "la historia universal". ${ }^{8}$ La educación se presenta así como equivalente a la historia. Este principio básico de la llustración, que Hampson define como "la cultura del hombre culto como abarcadora de la totalidad de sí mismo"' es un precedente del concepto antropológico de la enculturación. La doctrina de la Mustración respecto a la "unidad psíquica" del hombre descansa en la creencia de que "en el estudio de las diferencias socioculturales, las diferencias hereditarias (genéticas) se anulan mutuamente entre sí, dejando a la experiencia como variable más significativa". Fueron Turgot y sus seguidores, especiaimente Helvetins, los que defendieron la idea de la "unidad psíquica" que posteriormente retoma la aniropología para construir la ciencia.
Como demuestra Marvin Harris -en un polémico y peculiar trabajo, aunque a nucstro entender, excelente; en su interpretación de la llustración:- "cuando Franz Boas escribió Mind of Primitive Man en 1911" reprodujo, sin saberlo, la argumentación de Turgot respecto a la universalidad de la razón al afirmar que "las disposiciones primitivas son tan activas entre los pueblos bárbaros como entre los civilizados. Probablemente son las mismas en todo tiempo y lugar". ${ }^{10}$ Harris argumenta que "una de las derivaciones más curiosas de la creencia de Locke en el poder del medio ambiente fue la popular suposición de que podían existir razas de hombres cuya situación cultural fuera tan precaria que resultaran indistinguibles de los animales. Jean Jacques Rousseau, en su Discurso sobre el origen y el fundamento de la desigualdad entre los hombres (1755), sostcría implícitamente que el poder de la educación era tan grande que permitiría lograr la transición del mono al hombre"."

En definitiva, uno de los principios básicos de la Пlustración, el de la "universalidad psíquica" del hombre, defiende la existencia del poder de la enculturación y la plasticidad e indefinición de la naturaleza humana, la cual es susceptible de perfeccionarse a través de un método que puedc hacer surgir al hombre del mundo animal y elevarlo, separándolo de su condición salvaje como parte de la naturaleza. De ello se deriva una suerte de unilinealidad consecuente del desarrollo de la razón como un curso universal y unificado que conduce a la "verdad" $y$ al "progreso" de la historia universal constituyendo el pilar básico de los principios universales del pensamiento científico moderno.

\section{La Ilustración como ruptura de lo sobrenatural. "Dejad haced, dejad pasar: el mundo marcha solo"}

Aunque el concepto de "progreso" se forjara con posterioridad -y la Ilustración no presentara, en opinión de varios autores, una "teoría del progreso" 12 -, algunos de sus más brillantes pensadores como Kant, Turgot y Diderot presentaron en sus interpretaciones de la historia una clara noción de avance mediante estudios acumulativos de la razón. La Ilustración interpretaba la evolución en términos dic progreso en el sentido de cambio hacia una mayor racionalidad en la acumulación de conocimientos para interpretar la realidad pero no en el sentido que la tecnología occidental significara progreso como sucedería después. En efecto, como analiza lúcidamente Pedro Ruiz Torres en su

6 HAFRIS, M. (1869), The Riso of Anthropological Theory, Foutiedgo \& Kegan, London, pp, 9 y 13.

7 Ver BACON, F. (1979), De angmentis scientlarum (1623), en The Works of Francis Bacon. (New York Hurd y Houghten 1863-72. vol 15). Vol 9, p. 14. Cf. el análsis de N. HAMPSON, The Enllghtenment. Hardmond Sworth. Penguit, pp. 37 y 38.

B TURGOT; A. R. J. (1844), "Plan de deux sur l'histare universale", en Ouvres de Turgot, Guillachmin, Paris, pp. 627 y 645.

9 HAMPSON, N.(1979), The Enlightenment, Penguin, Harmondswonh, p, 11.

10 TURGOT, A. A. J., op, cit. p. 645.

11 HARPIS, M., op. cit. pp. 15 y 16.

12 Ver GAY, P. (1964), The Party of Humanity, Knopt, New York.pp. 270 y ss. y (1966), The Enlightenment: an interpretation. The Rise of Modern Faganism, Knopt, New York, passim: HARAIS, M., op. cit. pp, $8 \cdot 52$. 
trabajo La época de la razón: La Ilustración, ${ }^{13}$ es el pensamiento ilustrado el que provoca el comienzo de la mutación que desencadena el proceso de la mođernización de las sociedades, durante el cual se rompería la subordinación del hombre a lo sobrenatural despojándose así la guía de la religión sobre la conducta humana. Aunque surja en Inglaterra, como una continuación natural de las corrientes racionalistas y empiristas del siglo XVII (de Descartes a Locke, pasando por Bacon, Galileo, Hobbes, Leibniz y Newton), la Hustración se asienta en Francia donde produjo el núcleo central de su pensamiento en el contexto del enciclopedismo ${ }^{14}$ como proyecto de realización de la Enciclopedia (1751-1765), "obra monumental dirigida a la opinión pública", según se indica en el Discurso preliminar de D'Alembert, "la obra de una sociedad de hombres de letras" que pretendía "tanto guiar a los que se sienten con valor para trabajar en la instrucción de los demás, como orientar a los que se instruyen por sí mismos". La voz dedicada a los "únicos y verdaderos filósofos" los definía como aquellos "en quienes la libertad de pensar se ha posesionado del razonamiento... porque se han atrevido a traspasar los límites sagrados de la reljgión, y han roto las trabas en que la fe encerraba la razón". Los filósofos, dice la Enciclopedia, son una minoría de hombres "libres de prejuicios religiosos", que sólo actúan después de la reflexión, a los que sólo obliga la razón (la única luz que guía en la oscuridad de la noche), que poseen un espíritu de observación y đe precisión y no están presos, como los demás hombres, de sus pasiones y creencias religiosas, ni se adormecen bajo el yugo de la superstición, atreviéndose a salir del cúrculo de las verdades estabiecidas, y caminar por nuevas rutas. ${ }^{15}$

Así, David Hume muestra, al aplicar su "principio de asociación de las iđeas"16 a la religión, cómo "el sentimiento religioso tiene su raíz en los sentimientos de miedo ante la muerte, de deseo de vida eterna, de terror ante lo desconocido" y cómo estas ficciones aún sin ser eliminables, por ser naturales, permiten, al explicar su origen, tomar conciencia de su carácter ilusorio y, por tanto, liberamos de su dominio sobre nosotros. ${ }^{17} \mathrm{De}$ igual forma Hume, al defender la "doctrina de la libertad", señala que "no hay método de razonamiento más común, ni tampoco más censurable, que el de intentar refutar en las disputas filosóficas cualquier hipótesis con el pretexto de que tiene consecuencias peligrosas para la religión y la moralidad. Si una hipótesis nos lleva a conclusiones absurdas es, ciertamente falsa, pero no es cierto que una opinión sea falsa por tener consecuencias peligrosas". ${ }^{18}$ De esta forma, a través de la configuración del "método experimental", la Ilustración asumió como objetivo escrutar al hombre, a la naturaleza y a la sociedad mediante la ciencia y la técnica.

Pero el elemento clave de la Ilustración desde la perspectiva de nuestra argumentación lo constituye "la construcción científica de los recursos naturales", tarea ésta que, en la configuración del pensamiento científico, quedó encomenđada a los economistas encargados de elaborar "la libertad mercantil" como cimientos sobre los que se apoyaría el futuro "liberalismo económico". Desde que Quesnay y sus discípulos (conocidos como fisiócratas) pretendieron descubrir "el ciclo económico", explicándolo como un esquema conceptual y señalando "cómo en cada periodo económico una masa de bienes nuevos penetra en la economía nacional proveniente, según ellos, del tesoro inagotable de la naturaleza"; ${ }^{19}$ desde entonces ésta, la naturaleza, quedó conceptualizada científicamente como una imagen positiva, el "factor tierra", $y$ así definida como un recurso dado e inmodificable pero con poderes sobrados para determinar la exparısión económica. El factor tierra era para el pensamiento ilustrado el centro del sistema explicativo de la economía: las recomendaciones de su programa "pueden reducirse a dos: el "laissez-faire", incluyendo el libre cambio, y el impuesto único sobre la tierra". 20

En realidad Quesnay, Turgot y su "fisiocracia" (dominio de la naturaleza) no pueden entenderse separados de su contexto histórico de los "estados agrícolas", donde, la revolución técnica agrícola suponía un muy rápido enriquecimiento para los propietarios agrícolas. En cierto modo, la "ideología bucólica de vuelta a la naturaleza" venía a justificar un orden social y la popularidad de la agricultura en la Europa del sigio XVIII suponían, de alguna manera, el reforzamiento de la monarquía despótica. "Le tableau economique muestra cómo cada clase vive, por la prosperidad de los terratenientes en condición de la prosperidad de las demás clases". 21

13 Ver FONTANA, J. (director)(1993), Historia Universal Planeta, Planeta, Barcelona, vol 9. pp. 20-121.

14 Movimiento intelectual vinculada al proyecto de elaborar en Francia una "enciciopedia" o Diccionario razonado de las cienclas, las artes y los aficios y aue, coma desarrollo de la Cyclopedla británica de Chambers (1728) de cuya traducción al frances partió, agilutinó a administradores, tácnicos, cientificos, artistas, industriales y comerciantes en torno a Denis Diderot (quien en un ptincipio iba a ser un mero traductor) como director del proyecto con apoyo de D'Alembert.

15 Ver RUIZ TORAES, P., "La época de le razón", en Fontana, J., op. cit. p. 32.

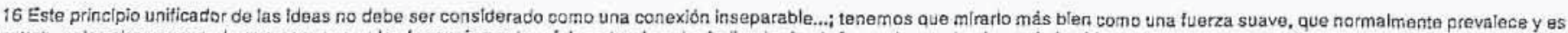

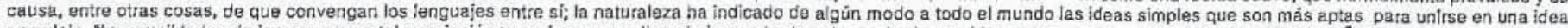

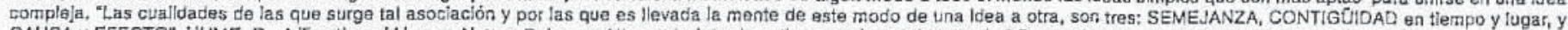

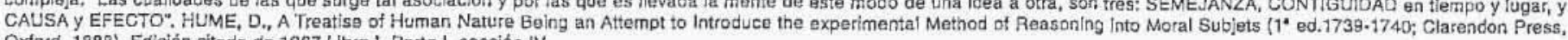
Oxford, 18B8). Edición citada de 1967.Lituro I, Parte I, sección IV.

1THUME, D.(1942), Diálogos sobre la religión natural, Colegio de México, México.

18 HUME, D., op. cit.

19 SCHUMPEIER, J. A.(1963), Sintesis de la evolución de la clencie económica y sus métodos, Occidente, Barcelona, p.63.

20 SCHUMPETER, A. A.(1955), History of EconomicAnalysts, Gearge Alten \& Unwin Ltt., London, p. 230.

21 SCHUMPETER, J. A., Ibid., P. 234. 


\section{La naturaleza como tesoro inagotable y reproducible como un reloj}

En su investigación Tiempo, disciplina de trabajo y capitalismo industrial, E. P. Thompson muestra como "con el avanzar del siglo XVII la imagen del mecanicismo de relojería se extiendc hasta que, con Newton, ha absorbido el universo...". Y hacia mediados del siglo XVWI el reloj ha penelrado en los niveles mâs íntimos de la sociedad.

Históricamente, el trabajo, guiado por la "lógica de la necesidad", estaba adaptado a los ritmos de la naturalcza. Para muchas culturas dominar, utilizar o ganar el paso del tiempo era algo que transgredía las reglas de la naturaleza. Esta lógica de la satisfacción de necesidades consideraba que la vida humana, como parte de la naturaleza, no pođía adquirir un pleno desarrollo sino intercambiando "usos" con la naturaleza. El establecimiento del "tiempo industrial" o lo que E. P. Thompson ha Ilamado "la orientación del tiempo al que hacer" como elemento clave en la construcción del capitaiismo ${ }^{22}$ inicia el proceso de transformación de las interacciones del hombre con la naturaleza en términos de "valores de uso" a transacciones en términos de "valores de cambio". ${ }^{23}$

La Iustración, maravillada por la mecánica, los inventos y la construcción de artilugios posibles e imposibles concibió, por primera vez, la posibilidad de comprender, explicar y reproducir la naturaleza en forma mecánica "descubriendo un concepto del tiempo abstracto y secularizado independiente de los acontecimientos". Siguiendo las ideas de Leibniz, Newton y Kant la llustración transformó la conciencia del tiempo de forma tal que, siglos más tarde, acabaría por someter las rutinas diarias a la rígida reglamentación de un tiempo industrial, compartimentado, objetivo y separado de la vida y subordinado a la lógica del lucro impuesta por el mercado.

Sin embargo, la Ilustración no presentó una idea clara de progreso, de contenido unilineal vinculado a la tecnología y al mercado; su preocupación era simplemente mostrar la superioridad del hombre sobre el resto de los seres vivos. En cierto sentido, la Ilustración mostraba aún claros prejuicios sobre el concepto de modernidad: determinados segmentos de la llustración cuestionaban la idea de progreso como dominio de la naturaleza. En efecto, Voltaire, seudónimo de Francis Marie Arouet, convirtió el reloj en el símbolo de las maravillas técnicas de la nueva época, mientras que Jean Jacques Rousseau, crítico con ella, percibía la otra cara del progreso y consideró el reloj como el signo más evidente del yugo de la razón y la civilización... El reloj no sólo se utilizó para medir el tiempo o situarse convenientemente en el espacio. Algunos cicntíficos y filósofos se imaginaron el universo y el organismo de los seres vivos como una gran máquina que funcionaba sola, con la misma regularidad, simetría y precisión que el reloj. Si el mundo era como un reloj, no había necesidad de que Dios - despućs de haberlo creado, dándole leyes para que funcionara- interviniera constantemente en él convirtiéndolo cn un escenario de acontecimientos sorprendentes y milagrosos. La mecánica del sistema de la naturaleza podía funcionar con la misma regularidad observada en el reloj, un objeto casi perfecto fabricado por el ser humano. No es extraño que la analogía con el reloj cambiara la forma de pensar del mundo y de pensarse a sí mismo que tenía el hombre. Reforzaba la idea de que, después de todo, la razón humana podía descubrir por sí misma las leyes del ritmo regular de la naturaleza, que funcionaba del mismo modo que esta máquina tan precisa inventada para medir el tiempo. ${ }^{24}$ Aunque el "factor tierra", la naturaleza, fuera un elemento central, aparece situado en un segundo término en el sistema económico, tras el factor trabajo que es el que, en definitiva, va acumulando el capital nccesario para poner en marcha cl proceso incustrial. "Sea cual fuere el suelo, clima o la extensión del territorio de una nación, la abundancia o escasez de su abastecimiento depende, en cada situación particular, de dos circunstancias diferentes: la primera de la aptitud, destreza y sensatc\% con que generalmente se ejercita el trabajo, y la segunda por la proporción entre el número de empleados en una labor útil y aquellos que no lo están". 25

Años más tarde, con el comienzo de la revolución industrial, se genera un modo de uso de los recursos naturales vinculado a la producción masiva de bienes y basado en la división del trabajo que convierte el trabajo en un nuevo mito, vinculado al mito ilustrado de la máquina. "Así empezó la larga historia de la subordinación de la gente a las máquinas hechas por la misma gente. El ser humano tiene que hacerse capaz de adaptarse a la máquina: una idea que hace necesario un cambio completo en la concepción fundamental del hombre. En lo sucesivo él es concebido como Homo laborans; puede realizar su naturaleza como ser humano sólo a través del trabajo. La producción mecánica muestra los requerimientos de lo que es apropiado a su naturaleza: es decir, de lo que ha de considerarse como virturoso. El nuevo catálogo de virtudes está dictado por las leyes operativas de la máquina, ejemplificada por la más perfecta de las máquinas", la que había permitido descubrir la naturaleza a la Dlustración, "el reloj: disciplina, precisión, orden, diligencia, limpieza, resistencia y puntualidad". Aunque las primeras generaciones de asaiariados opusieron fuerte resistencia a su subordinación a la industria fabril y a su tortura física y psicológica, las iglesias y las escuelas se encargaron de implantar en los trabajadores las semillas de las virtudes que demandaban las máquinas" ${ }^{26}$ y que exigiría el progreso.

22 Ver THOMPSON, E. P.(1967). Time, Work-Discipline and Industriat Capitalism", en Past and Present. Ne 38, December, pp. 56 - 87.

23 Ct. Articuto de TOL,EDO, V. M., en SEVILLA GUZMÁN, E. y M. GONZÁt.eZ DE MOLINA (1993). Ecologia, Campesinado e Histaria, La Piqueta, Madrid.

24 Ver RU/Z TORRES, P., op.cit, pp. 24 y 26.

25 SM:TH, A.(1958), La riqueza de las naciones, F.C.E., México, p. 3.

26 Ver GRONEMEYER, M.(1995), "Helping"; en SACHS, W. (Ed.) The Development Dictionary. A Guide to Knowledge as Power, $2^{\circ}$ de Books, London, pp, 53-69; pp. 57 y 58. 
La actividad científica se basaba en la asunción de que la naturaleza y la sociedad, como objeto de análisis, podían ser separados del sujeto que los estudiaba. Eso dio por resultado una ciencia dividida en parcelas de conocimiento y el mito de una ciencia neutral, libre de valores que legitima a los intelectuales "puros" o científicos. "En otras palabras, lo Verdadero conduce al Bien. La racionalidad se convirtió en "racionalidad científica" y el conocimiento fue sinónimo de "conocimiento científico". Otras formas de conocimiento y otras apelaciones a la racionalidad, como el conocimiento práctico agrícola, medicinal o artesanal, fueron consideradas como de segunda categoría" (Funtowitcz Ravetz, 1996: 7).

Lo que definimos como ciencia es, sobre todo, un producto social de lo que puede ser caracterizado como "sistema científico"; es decir, toda construcción epistemológica es el resultado de una situación sociocultural de naturaleza histórica, por lo que el método científico no garantiza la separación absoluta entre razón y pasión. Dicho de otro modo, la "ciencia" se ve afectada por el contexto intelectual, y la praxis intelectual y política de quienes la producen ya que el sistema científico, incluyendo la tecnología basada en él, constituye un fenómeno social que, para su análisis, requiere la aplicación de los cambiantes teoría y método científicos; y por tanto, considerar tanto el pensamiento científico convencional como el alternativo, tal como han sido caracterizados anteriormente. "La historia de cualquier ciencia, sin embargo, puede escribirse - y de hecho se escribe- como si se tratara de un fenómeno independiente, como si fuera la historia de una progresión del intelecto humano. Por supuesto, las interrelaciones de la ciencia con la sociedad no niegan un cierto grado de autonomía a la actividad científica, $y$ afirman, por otra parte, la capacidad de la ciencia para ejercer sobre la sociedad una acción crítica y transformadora. En consecuencia, constituye un error tan grave como el anterior escribir la historia de la ciencia como un mero reflejo de las presiones, las exigencias y los conflictos de la sociedad. Lo que es más peculiar de la ciencia, en definitiva, resulta aquello que acaba por transformar el objeto mismo de su estudio y de su actividad: la naturaleza y la sociedad" (Palerm, 1980: 14).

\section{Modernización y cientificación}

El concepto de "modernización" (Habermas, 1989) se incorpora a la "literatura científica" en los años cincuenta. Caracteriza un enfoque teórico que hace suyo el problema de Max Weber a través de una elaboración técnica realizada con las herramientas del funcionalismo sociológico. "El concepto de modernización se refiere a una gavilla de procesos acumulativos y que se refuerzan mutuamente: a la formación de capital y a la movilización de recursos; al desarrollo de las fuerzas productivas y al incremento de la productividad del trabajo; a la implantación de poderes políticos centralizados y al desarrollo de identidades nacionales; a la difusión de derechos de participación politica, de las formas de vida urbana y de la educación formal; a la secularización de valores y normas, etc. La teoría de la moder- nización práctica es, en el concepto de modernidad de Max Weber, una abstracción preñada de consecuencias. Desgaja la modernidad de sus orígenes moderno-europeos para esterilizarla y convertirla en un patrón de procesos de evolución social neutralizados en cuanto al espacio y al tiempo". Con elio se generaliza una teoría de la evolución "que no necesita quedar grabada con la idea de culminación o remate de la modernidad, es decir, de un estado final tras el que hubieran de ponerse en marcha evoluciones "posmodernas". Así, al desprender la modernización de sus orígenes históricos un observador científico, puede desprenderse del racionalismo occidental, con lo que "los procesos de modernización, que siguen discurriendo, por asî decirlo, de forma automática, pueden relativizarse desde la distanciada mirada de un observador posmoderno". Se construye así una modernización que se "limitaría a ejecutar las leyes funcionales de la economía y del Estado, de la ciencia y de la técni$\mathrm{ca}$, que supuestamente se habrían aunado para constituir un sistema ya no influíble" (lbid.p., 12-13). Esta incontenible aceleración de los procesos sociales constituye el cemento con el que se forjan las sociedades posindustriales o capitalistas avanzadas.

Una de las características clave de tales sociedades posindustriales o modernas lo constituye el papel que juega en ellas la innovación científica y tecnológica: a través de ellas se pretende el control social del cambio, anticipando el futuro con el fin de planificarlo. La ciencia y la tecnología permiten, al fin, legitimar la acción social con una nueva ética tecnocrática que sustituye a la religión y proporciona al hombre moderno una interpretación fidedigna de la naturaleza y la sociedad, transformándose con ello en la «ideología» de las sociedades posindustriales.

Como acabamos de ver, ha sido Habermas quien, continuando la tradición de la Escuela de Francfort, construye una teoría crítica de la sociedad capitalista posindustrial (Tbid.: 1968, 1969; Solé, 1988,p., 17-29). En ella la conciencia tecnocrática desamollada a través de la ideología científica diluye la relación capital-trabajo reinterpretando a través de una ilusión racionalizadora la explotación y la opresión: "la consciencia tecnocrática refleja no sólo la separación de una situación ética sino que mantiene al hombre aparte de la represión que la ética, como una categoría de la vida, puede ejercer sobre él" (Habermas, 1972 : 353-375, 373). Así pues, la nueva fórmula de legitimación que proporciona una interpretación del mundo para el hombre moderno lo constituye la extensión de los principios científicos a cualquier ámbito de explicación. El núcleo central del capitalismo avanzado es, pues, la institucionalización de la investigación científica capaz de transferir la revolución tecnológica que experimentó en la industria a las demás actividades del hombre. Se desarrolla, así, un proceso de cientificación que en su aplicación a la "política concuerda entonces automáticamente con la teoría desarrollada por Weber, extendida por Schumpeter, y ahora cuestionada por la moderna sociología política, una teoría que en su último análisis, reduce el proceso democrático de toma de decisiones a un procedimiento đe aclamación regulada para que las élites designadas se alternen en el ejercicio del poder. De esta forma el poder, intocable en su sustancia irracional, puede ser legitimado pero no racionalizado" (Ibid.p., 68). 
El carácter opresor de la ciencia y la tecnología es conceptualizado por Marcuse en los siguicntes términos: "el progreso técnico multiplicó las necesidades y las satisfacciones, en tanto que su utilización convirtió tanto a las necesidades como a las satisfacciones en represivas: ellas mantienen por sí mismas el sometimiento y la dominación" (Marcuse, 1983:411). Tal carácter es reinterpretado por Habermas mediante el concepto de racionalización que conduce supuestamente a la racionalidad formal frentc a la racionalidad instrumental (1984: 54 y ss). Así, el desarrollo tecnológico y sus aplicaciones en la economía de las sociedades avanzadas pone de manifiesto un nuevo tipo de racionalidad: la racionalidad científico-técnica y, con ella, la cicntificación del hombre y la naturaleza. Ello significa que la agricultura industrializada puede artificializar la naturaleza reproduciêncola a través de la ciencia y, por tanto, aportar algo decisivo en la configuración de la estructura social del mundo rural de las sociedades posindustriales: el hombre puede, a través de la tecnología, separarse de la naturaleza, dominarla y, finalmente, ser el rey de la creación. La moderniración puede conseguir reproducir la naturaleza y, por consiguiente, volver a crear aquello que con su tecnología científica destruye; destrucción ésta fugaz, ya que no necesita mantener unos mecanismos de reproducción natural desde el momento en que el hombre, a través de la ciencia, puede volver a configurar de nuevo algo que previamente destruye: la ciencia no tiene límites: es el dios de la modernidad y es necesario sacrificar al carnpesinado en sus altarcs (Sevilla Guzmán y Gincr, 1980: 13-27).

Comienza a gozar dc una general aceptación el imputar a la dimensión internacional que adoptan los sistemas productivos que controlan la mercantilización de los recursos naturales la responsabilidad central de la crisis ecológica que atravesamos a nivel planetario. En efecto, en la última década han crecido los trabajos científicos y la divulgación crítica en torno a este tema, quedando nítidamente asentado el aserto de que el manejo industrializado de los recursos naturales rompe las tasas de reacomodo y reposición de los residuos produciendo un creciente incremento de entropía. La posibilidad de reutilización de tan sólo una parte de los residuos origina que éstos se transformen en distintas formas de contaminación y generen una creciente pérdida de aptitud productiva de los recursos naturales.

Son múltiples las formas de resistencia de la agricultura basada principalmente en cl trabajo familiar y cn unidades de producción constituidas por grupos domésticos, sean de naturaleza campesina (Sevilla Guzmán, 1991a: 366-399) o de producción simple de mercancías agrarias (Friedmann, 1978 : 545-586; 1980 : 158-184), basándose fundamentaimente en la propiedad individual de la tierra y en la naturaleza refractaria de los procesos biológicos y ecológicos incluidos en la producción agraria al requerir éstos, en muchos casos, atención individual en intercambios naturaleza - sociedad en términos de valores de uso (Toledo, 1993). No obstante, existen multitud de formas históricas de resistencia a la penetración cada vez mayor por el capital en la agricultura (Goodman et al., 1986: 20-40).

\section{Ciencia, riesgo y ética ambiental}

A finales del siglo XX los científicos sociales, especialmente en Europa, han comenzado a analizar el creciente interés de la gente por temas como la globalización y el cambio medioambiental. Beck, en su clásico libro La sociedad del riesgo (1992), (originalmente publicado en alemán en 1986), sugicre que en las postrimerías del siglo $\mathrm{XX}$, las fucrzas productivas de la socicdad industrial en Europa han "perdido su inocencia". El aumento del pođer desde el "progreso" tecnoeconómico, está siendo crecienternente oscurecido por la producción de riesgo... (y la)... lógica de la producción y distribución de riesgos se desarrolla en comparación con la lógica de la distribución de riqueza" (Ibid.p., 12-13). Así, mientras que la ciencia y la tecnología industrial han mantenido hasta aquí el equilibrio entre el crecimiento de la población y la producción de alimentos, las consecuencias medioambientales de este logro parecen amenazar las bases ccológicas de la vida misma. Sin embargo, como Beck sugierc, nuestro sentido industrial del "estar en riesgo" es tanto producto de nuestro modo de vida industrial, como de una crisis medioambiental "real". El riesgo se identifica con nuestra dependencia de un sistema de producción, distribución y consumo experto y globalizado, que nos aliena de las demás personas y del resto de la naturaleza. Tales sistemas pueden tener consecuencias inesperadas -como son la pérdida del hábitat natural y la vida salvaje, la aparición de enfermedades como la encefalia bovina, también llamada enfermedad de las "vacas locas", o la más reciente contaminación por dioxina de los alimentos ocurrida en Bélgica. Cuando tales "accidentes" ocurren, frccuentemente, somos capaces de responder, pero, sin embargo, no somos hábiles para prevenirlos. Debido a su complejidad, estos riesgos pueden ser extremadamente difíciles, si no imposibles de intcrpretar, puesto que generalmente llegan a nosotros bajo la forma simplificada de åsperos debates entre científicos y políticos. Como Irvin puntualiza: "un tema inusual en los debates y controversias medioambientales se refiere a la cuestión de la naturaleza del conocimiento medioambiental -de como identificamos y medimos la destrucción medioambiental y las amenazas relacionadas con el medioambiente, con nuestra supervivencia y modos de vida". Mientras que el tratamiento con éxito de los temas medioambientales parece necesitar definiciones autorizadas y claras del riesgo y la amenaza, las explicaciones cientificas frecuentemente luchan por conseguir legitimidad política, como lo testifican ampliamente los casos recientes sobre seguridad alimentaria y polución ambiental, y por ello, "el conocimiento medioambiental se ha convertido en un ámbito diverso y cuestionado" (1997: 218).

Las consecuencias no deseadas de la producción, distribución y consumo industriales y globalizados, y la naturalcza del conocimiento experto, aparcntemente cucstionada, han dado como resultado una pérdida de fe en la ciencia, la verdad y el progrcso. Esta pérdida de fe en "el contexto de nuestra existencia altamente tecnificada, es un elemento clave en el surgimiento contemporáneo del riesgo y la inseguridad, to que sugiere que la crisis medioambiental es tanto una crisis de nuestras modemas instituciones y creencias sociales, como de naturalcza extema". 
A pesar del medio siglo de esfuerzos por el desarrollo, la diferencia entre ricos y pobres ha aumentado. Como Esteva y Illich apuntan: "el desarrollo promucve riqucza, pero para la mayoría sólo significa la modernización de su pobreza y cl aumento de la dependencia de la dirección y administración de los otros" (1986: 6).

En suma, la producción, distribución y el consumo industrial moderno han producido respuestas medioambientales no esperadas que parecen amenazar la integridad y sustentabilidad dcl sistema ecológico del que la vida humana depende. Tales polarizaciones socioeconómicas y tal depredación ecológica han generado una pérdida de fe en la autoridad de la ciencia y en la legitimidad de los gobicrnos supucstamente democrálicos que incrementa la situación de riesgo y es parcialmente responsable de la crisis actual.

\section{Ciencia: ¿estructura social o control del riesgo?}

La ciencia, en general, puede ser definida como el conjunto de mecanismos que, mediantc la utilización de la investigación y el pensamiento teórico y lógico-argumental, pretende describir sistemáticamente, explicar y predecir la realidad (natural o social) para generar un cuerpo de conocimientos, contrastados empíricamente, que permitan entenderla. Existen, por tanto, formas de indagación específicas de la ciencia que, a través de un proceso presumiblemente acumulativo, han ido variando en el tiempo, pretendiendo perfeccionarsc. Tal es el caso de la inducción (generalización a partir de la interpretación de observaciones) y la deducción (obtención de conclusiones a partir de la articulación lógica de varias proposiciones que se suponen válidas). Ambas suelen articularse cn procesos más amplios de indagación. De entre ellos, la forma más acabada es la hipotético-deductiva. Consiste ésta en la formulación de hipótesis capaces de explicar determinados fenómenos sobre los que poseemos información previa. Tales hipótesis se encuentran en el contexto de una teoría que explica determinada parcela de la realidad cuyo conocimiento queremos ampliar.

EI paso siguiente consistc en operativizar, de alguna manera, las hipótesis, de forma que podamos (en ellas mismas, o cn sus consccuencias observables, obtener derivaciones lógicas deducidas a partir de ellas) contrastarlas con la realidad mediante experimentos diseñados para ello, o en general, a través de técnicas generadas para la obtención de datos.

Se llega así a obtener evidencia empírica en la dirección apuntada por la hipótesis, o a falsar ésta, en cuyo caso, habría de abandonarse, o reformularse. De obtenerse sucesivas evidencias favorables a una hipótesis, esta será admitida (en forma provisional) como válida, pasando así a integrarse en el contexto teórico formulado (Popper, 1974: 73 y ss.).

Probablemente, la operación clave de la ciencia se encuentre en su pretensión de "romper cl discurso ideológico que cubre sus objetos", tengan éstos una "realidad" social o natural. Tal tarea se lleva a cabo pretendiendo obtener la objetividad del investigador al conseguir un modo de obscrvación que neutralice su ideología. En el caso de las llamadas "ciencias naturales" -que se enfrentan a objetos de sí no hablantes-, ese discurso había de ser dejado de lado ya que aunque fuera desconstruída nada podría reconstruirse con sus piezas: por eso recurrieron a la manera menos discursiva de las prácticas significantes, la estadística. En el caso de las ciencias sociales -que se enfrentan a objetos hablantes-, ese discurso había de ser desconstruido para reconstruir con sus piezas otro discurso cientifico: pero en una primera ctapa sc recurre a la estadística para romper el discurso ideológico que recubre el objeto, "aunque inconscientemente se vuelva a recubrir con otro discurso, pretendidamente científico, pero ideológico en cuanto no es posible trascenderlo" (Ibáñez, 1985: 207). Es éste el mecanismo a través del cual la ciencia pretende aprehender la realidad generando datos susceptibles de ser manipulados mediante artificios de contrastación empírica. De esta manera la ciencia utiliza una forma de conocimiento atomista (el todo es la suma de las partes), mecánico (los sistcmas se mueven de un equilibrio a otro), universal (existen principios generales) y monista (el conocimiento parcial puede integrarse en un todo coherente).

Ante estas premisas, sobre las cuales la ciencia elabora su forma de escrutar la realidad, la agroecología, aceptando la biodiversidad ecológica y sociocultural y partiendo de la necesidad de aceptar otras formas de conocimiento distintas al conocimiento científico, elabora las siguientes premisas altemativas: para generar un conocimiento holístico (las partes no pueden entenderse fucra de su totalidad la cual es distinta a la suma de sus partes), sistémico (los sistemas son evolutivos y aunque puedan ser mecánicos, o determinísticos son no predecibles), contextualizador (son contingentes respecto a un gran número de factores particulares en el tiempo y el espacio), subjetivo (no pueden conocerse fuera de nuestras actividades y valores) y pluralista (los sistemas complejos sólo pueden conocerse a través de pautas de conocimiento alternativas que son necesariamente simplificaciones de la realidad) (Nogaard, 1994: 61-80).

Históricamente, para el método analítico utilizado por la ciencia, la rcalidad ha de diversificarse en diferentcs dimensiones, para, escrutando cada una de ellas por separado, integrarlas después y obtener una visión cabal de la misma. La primera separación consiste en diferenciar el mundo físico o natural del mundo social. Después, cada una de estas grandes parcelas permite ulteriores diferenciaciones. Aparecen así las ciencias naturales (física, química, biologia, gcología...) y las ciencias sociales (economía, sociología, antropología, historia...). Sin embargo, como enfatiza la agroccología, la realidad, tanto física como social, constiturye un todo en evolución, de forma tal que el hombre, como un animal más, transforma la realidad y se transforma a sí mismo, en una interacción recíproca.

En efecto, si seguimos el razonamiento del sociólogo Edgar Morin (1967) y analizamos lo que la cicncia ha aportado al desarrollo del bienestar humano $\mathrm{y}$ al avance tecnológico a $\mathrm{cl}$ vin- 
culado, observamos que, junto a los logros de la sanidad, el nivel de instrucción y, en general, el bienestar material del "primer mundo", aparecen otros males que, "específicamente modernos" (supcrpoblación, polución, degradación ecológica, aumento de las desigualdades, amenaza termonuclear), resultan como dice Wojciechoowski (1978), "inseparables de los progresos del conocimiento científico. Inconscientes de lo que la ciencia es y hace en la sociedad, los científicos se sienten incapaces de controlar los poderes sojuzgadores o destructores surgidos dc su saber". El problema es el siguiente: "se puede comer sin conocer las leyes de la digestión, respirar sin conocer las de la respiración, se puede pensar sin conocer las leyes ni la naturaleza del conocimiento, pero no se puede, como hace el hombre de hoy en día, hacer ciencia e implementarla en tecnologías sin tencr conocimiento de ese conocimiento" (Morin, 1985: 13).

En cste contexto, la ciencia (incluidas las tecnologias de ella derivadas) puede ser considerada como una forma específica de escrutar la realidad basada en la simplificación de la complejidad para, mediante un conocimiento abstracto, generar su sistema social de gestión del riesgo a no equivocarnos (J.Ravetz y S. Funtowicz, 1990 y 1994: 189-196). El hecho de que el extraordinario desarrollo de las tecnologías derivadas de la ciencia haya generado en el hombre la creencia de poder obtener un dominio sobre la naturaleza, sintiendo la ilusión de encontrarse fuera de ella, ha determinado que el hombre utilice la ciencia, como estructura social, mediante el consenso de su "sistema do expertos", lo que obliga a la agroecología a buscar elementos de control a la hora de intervenir en el establecimiento de las normas y limitcs ambientales "científicamente indiscutibles".

\section{Ciencia y ética ambiental}

Es en este contexto donde cabe situar a la agroecología que, aunque pretenda el manejo ecológico de los recursos naturales, y tenga, por tanto, como objeto la agricultura, ganadería y forestería, lo hace explicando las formas de degradación de los recursos y generando sistemas de contención, reposición y rcgencración. Ello supone introducirse en aquellas árcas de conocimiento que le permitan entender, analizar y predecir los fenómenos sociales, económicos, culturales y políticos que generan tales formas de degradación.

La agroecología no es una disciplina nueva, sino un nuevo campo de estudio que, por su enfoque, requiere combinar los hallazgos de diferentes disciplinas. Como señala Joan Martinez Alier (1998) es necesario lievar a cabo una "orquestación de las ciencias" donde los distintos hallazgos sean coordinados y las contradiccioncs e incompatibilidades sean abordadas para encarar su resolución. No se trata de caer en ningún reduccionismo, ni de buscar una utópica unificación de la ciencia, sino de aceptar un pluralismo metodológico (Nogaard, 1989), donde los límites de los juicios de autoridad de cualquier experto sean aceptados. En este sentido, "el conocimiento práctico de las poblaciones indígenas y los campesinos sobre biodiversidad agrícola es, a menudo, igual o superior al conocimiento experto occidental, mientras que en la naturaleza de muchos problemas socioecológicos actuales, de gran importancia y urgencia, donde los valores están en disputa y la incertidumbre (que no se reduce a riesgos probabilísticos) es grande, observamos que el campo de los "cvaluadores" competentes para dar una opinión va mucho más allá del estrecho círculo de los expertos autorizados" (Martíncz Alier, 1998: 74).

La ciencia convencional no permite, sin embargo, algo que resulta imprescindible hoy, ante su crisis epistemológica: la aparición de una epistemología participativa de carácter político, en la cual "todos los actores sociales interesados tengan algo importante que decir sobre el objeto y producto de la ciencia, generándose así, una comunidad extendida de evaluadores" (Funtowitcz y Ravest, op. cit.; Martinez Alier, 1999: 97). Es ćsta, la propuesta de la agroecología ya que, como consecuencia de su trabajo a nivel local, termina por defender -junto al pluralismo metodológico (orquestador de ciencias)- un pluralismo epistemológico, modificador de la naturaleza (de estructura social "elitistamente selectiva") de la ciencia convencional, ya que la existencia de alguna autoridad ajena a ella en la estructura social de control epistemológico podría transformar la naturaleza actual del riesgo a obtener una validación meramente parcial de su verdad, pudiendo incorporar, así, una dimensión ética que por sí sola es incapaz, en la actualidad, de incorporar a su pesquisa.

En el contexto del neoliberalismo y la globalización cconômica, en los términos más arriba definidos, el discurso ecotecnocrático de la sostenibilidad ${ }^{27}$ ha permitido la aparición de lo que Enrique Leff define como neoliberalismo ambiental. ${ }^{28}$ Este puede ser definido como la estrategia generada para legitimar la desposesión de los recursos naturales y culturales de las poblaciones dentro de un esquema concentrado, globalizado, donde sea posible dirimir los conflictos en un campo neutral. El objetivo último es transformar la naturaleza en capital natural al que las poblaciones indígenas atribuyen un valor $y$, así, que su biodiversidad y saber tradicional pueda ser cedido, tras una compensación económica a las empresas transnacionales de biotecnología, las cuales "serian las instancias encargadas de administrar racionaimente los 'bienes comunes', en beneficio del equilibrio ecológico, del bienestar de la humanidad actual y de las generaciones futuras" (Ibid.p., 26). Frente a esta amenaza, emerge, como una construcción imprescindible, la ética ambiental, a modo de rearme moral surgido de las luchas de resistencia de las comunidades indígenas y campesinas plasmado en su lógica de intercambio históricamente sustentable entre la naturaleza y la sociedad y traducida al lenguajc de la modcrnidad por el paradigma alternativo de la sustentabilidad. 
Desde la agroecología se han aportado no pocos elementos al mismo; así partiendo de un antiguo trabajo de Victor M. Toledo, es posible diferenciar cinco formas de conciencia vinculadas a la construcción del citado paradigma: a) conciencia de especie (la ticrra no es legado de nucstros abuclos, sino el préstamo de nuestros nietos); b) conciencia de identidad (como construcción desde el mundo vivido y lo endógeno de la rcproducción biótica y social); c) conciencia de género (como ruptura del lastrc histórico del patriarcado); d) conciencia intrageneracional (al superar la subordinación grupal vinculada a la edad) y d) conciencia de explotación (la asunción de lo propio desde la situación de pertencncia de cualquier forma de exclusión social).

En definitiva la ética ambiental, en construcción, propone un sistema de valores asociado a una racionalidad alternativa respecto a la producción y al consumo, donde la moral individual y los dercchos colectivos sc articulen a la conservación de la naturaleza y la sociedad respecto a la heterogeneidad étnica y culturai y a la diversidad biológica.

\section{A modo de conclusión: la ciencia como legitimadora del ecocidio cultural de la modernidad}

Como venimos analizando a lo largo de este artículo, durante el siglo XVII se configura una nueva manera de generar conocimiento: la ciencia; ésta separa al hombre de la naturaleza, haciéndolo sentirse fuera de ella y capaz de dominarla. Concomitantemente surge el neoliberalismo histórico que atribuye ał mercado una nueva condición de naturaleza: aquella que es capaz de establecer una nueva justicia, la mercantil; como consecuencia se inicia un proceso de mercantilización de la naturaleza y de la sociedad. El etnocentrismo científico de la identidad sociocultural occidental, configura entonces el concepto de modernización como el camino ineluctable a seguir por todos los grupos humanos; en él la productividad destaca como el elemento central que se extenderá en todos los ámbitos de las relaciones humanas. Resumiendo, "la idea eje" de este trabajo es que la ciencia y la tecnología son, en el pensamiento liberal, las legitimadoras de los procesos de modernización responsables de la homogencidad sociocultural que invade durante el siglo $\mathrm{XX}$ al proceso histórico.

Es importante destacar que los cambios que la modernidad ha producido en América Latina se han dado como ruptura con el pasado, transplantando y copiando las formas de vida y la organización socioeconómica de la identidad occidental, al llamado "nuevo continente". El pensamiento científico convencional es el resultado de la interacción entre el quehacer científico y las presiones de los centros de poder de la sociedad, que utilizan éste para legitimar sus formas de dominación.

El proceso de modemización, a través de la innovación científica y tccnológica, ha producido, entre otros, un quiebre en la relación hombre - naturaleza y su aplicación en América Latina llegó a constituir una auténtica agresión cultural. Los grupos sociales indígenas aparecen como residuos anacrónicos en esta dinámica: no existe lugar para ellos, son los excluidos por su incapacidad para aceptar la nueva ética del mercado.

La búsqueda de apoyo con las naciones desartolladas produjo una mcjora en los intercambios comerciales, pero, por otro lado, una concentración del poder económico, un desarrollo dependiente con pérdicia de integración social, fragmentación y desigualdad que sc unen a la referida exclusión de los pueblos indígenas. Hablar hoy de modernización y globalización implica reconocer que el desartollo del capitalismo se ha impuesto en todas partes. Los grupos indígenas han sido relegados a espacios marginales donde la productividad y eficiencia capitalistas no eran posibles y el uso múltiple del territorio que aseguraba la biodiversidad desaparece como tal: surge así una pérdida del papcl histórico que el mancjo indígena de los recursos naturales ha jugado respecto a la reproducción de las bases bióticas de la naturaleza. El resultado es que la agricultura industrializada, que incorpora la ciencia, sc expande por el plancta: tras conquistar las zonas húmedas y templadas mediantc las semillas mejoradas de alto rendimicnto que trajo la Revolución verde, pretende ahora apropiarse de las áreas frágiles mediante arreglos transgénicos donde era impensable introducir este tipo de agricultura, que deteriora a la naturaleza y a la sociedad.

Como hemos mostrado anteriormente, la agroecología, con su crítica al pensamiento científico convencional y su propuesta de sustentabilidad, está gencrando, en la actualidad, un consenso respecto a la perversidad del proceso que conduce a la antigua "economía de mercado" a una "sociedad de mercado", donde es posible patentar la vida biológica y social en pos del "progreso universal".

\section{Bibliografía}

ALAVI H. y SHANIN, T. (Eds.) (1982), introduction to the Sociology of "Developing Societies", Macmillan, London.

ALAVI, H. (1982), "The Structure of Peripheral Capitalism", en Alavi Shanin Eds., Intro-duction to the Sociology of "Developing Societies", Macmillan, London, pp. 162-192.

ALONSO MIELGO, A.M. (1993), Valoración tecnológica y fijación de prioridades de investigación en el cultivo de! arroz en España, Trabajo de Investigación Fin de Carrera. ETSIAM. Córdoba, España.

ALONSO MIELGO, A.M. y SEVILLA GUZMÁN, E. (1995), "El discurso ecotecnocrático de la sostenibilidad", en Cadenas Marín Ed., Agricultura y desarrollo sostenible, MAPA, Madrid.

ARNOL.D, R. W., I. SZABOL.CS Y TAAGULIAN, V. O. (1990), Global So:! Change, liASA, Laxenburg, Austria.

AVILES, J. (1992), "Situación de la eutrofización en España", en Revista de Ingenieria Civil (CEDEX), 86.

BAANEY, G. O. (1982), El mundo en el año 2000. En los albores del siglo XX!, informe técnico, Tecnos, Madrid.

BECK, U. (1998), ¿Qué es la globalización? Falacias del globalismo, respuestas de la globalización, Paidós, Barcelona.

BELL, C. y NEWBY, H. (1974), "Capitalist Farmers in British Class Structure", en Sociologia Ruralis, Vol. 14, (1/2): 86-107.

BELI., D. (1974), The Coming of Post-industrial Society, Heihemann, London. BELLLAPART, C. (1996), "Peligrosidad de nuestra alimentación. Carácter patogénico de nuestra alimentación industrializada", en Nueva agricultura biológica en equilibrio con la agricultura química, Mundi-Prensa, Madrid. BERNARDO, J. M. (1993), "El apogeo del liberalismo económico", en Historia de! Pensamiento, Vol. III, Juan Manue! Prado Director, Orbis, Barcelona. 
BUTTEL, F. (1979), "Estructura agraria y ecologia rural", en Agricultura y Sociedad, № 13., MAPA, Madrid.

CACHO, J. y SAINZ DEAJA, M. J. (1989), El agujero de ozono, Tabapress, Madrid.

CAPORAL, F.R. (1998), La extensión agraria del sector público ante los desaffos del desarrollo sostenible: el caso de Rilo Grande do Sul, Brasil, Tesis Doctoral del ISEC, Universidad de Córdoba, España.

CANUTO, J. C. (1998), Agricultura ecológica en Brasil: Perspectivas socioecológicas, Tesis Doctoral del ISEC, Universidad de Córdoba, España. CARAOL, R.C., VANDERMEER, J.H. y ROSET, P. (Eds.) (1990), Agroecology, MacGraw-Hill, New York.

CASTELLS, M. (1996), The Information Age: Economy, Society \& Culture, Blackwell, Cambridge, Mass. (vol.: 1996, 1997 y 1998. Citados la edición castellana de Alianza Editorial, 1997, 1998 y 1998).

CHAMBERS, R., PACEY, A. y THAUPP, L.A. (Eds.) (1989), Farmer first farmer innovation and agricultural research, Intermediate Technology Publications, London.

COMPAS-AGRUCO (1998), Plataforma para el diảlogo intercultural sobre cosmovisión y agricultura, AGRUCO, Cochabamba, Bolivia.

CONWAY, G.R. y BARBIER, E.B. (1990), After the Green Revolution, Earthscan Publications, Londion.

COSTABEBER, J.A. (1998), Acción colectiva y procesos de transición agroecológica en Fio Grande do Sul, Brasil, Tesis Doctoral del ISEC, Universidad de Córdoba, España.

CROSBY, A.W. (1996), Ecological imperialism. The biological expansion of Europe, 900-1900, Cambridge University Press, Cambridge.

DAVIS, J. M. (1956), "From agriculture to agribusiness", en Harvard Business Reviews, 34: 107-115.

DAVIS, J. M. y GOLDBERG, R.A. (1957), A concept of Agribusiness, Harvard University Press, Boston.

DEL.GADO, F. (1992), Agroecologia en las estrategias del desarrollo rural. Una experiencia institucional, AGRUCO, Cochabamba, Bolivia.

DELGADO, F. y SANCHEZ DE PUERTA, F. (1997), Hacia un sistema holisitco de información y conocimiento agrario: los casos de AGRUCOCochabamba y el ISEC- Córdoba, AGRUCO, Cochabamba, Bolivia. FERNANDEZ DURAN, R. (1993)، La explosión del desorden, Fundamentos, Madrid.

FAIEDLAND, W. H. (1972), "Technological trends and the organization of migrant farm workers", en Social Problems, № 19.

FRIEDLAND, W. H. (1976), "Tomato technology", en Society, $N^{2} 13$

FRIEDLAND, W. H. (1984), "Commodity systems analisys: Andalucia approach to the sociology of agriculture", en Research in Rural Sociology and Developpement, $N^{0} 1$.

FRIEDMANN, H. (1978), "World market, state and family farm: social bases of housenold production in the ear of wage jabur", en Comparative Studies in Society and History, 20.

FRIEDMANN, H. (1980), "Household production and the national economy", en The Journal of Peasant Studies, 7 (2).

GADGILM. y GUHA, R. (1992), This fisured land an ecological history of India Oxford Uriversity Press, Delhi. (Hay version casteliana en His. toria y Ecología, González de Molina y Martinez Alier Ecs.., Marcia! Pons, Madrid, 1993.

GLIESSMAN, S.R. (1997), Agroecology. Ecological processes in sustainable agriculture (En prensa).

GONZÁLEZ DE MOLINA M. y SEVILLA GUZMȦN, E. (1992), “Una propuesta de diálogo entre socialismo y ecologia: el neopopulismo ecológico", en Ecología Politica 3.

GOODMAN, D. E. y REDCLIFT; M. (1986), "Capitalism, petty comodity production and the tarm enterprises", en Agniculture. people and policies, Cox, Lowe y Winter Eds., Alien and Irwin, London.

GRONEMEYER, M. (1995), "Helping", en The development dictionary. A guide to knowledge as power, Sachs Ed. (1995), Books, London.

HABERMAS, J. (1968), Toward a rational society, Heinemann, London. HABERMAS, J. (1969), Cognition and human practice, Beacon Press. HABERMAS, J. (1989), El discurso filosófico de la modemidad, Taurus, Madrid.

HABERMAS, J. (1972), "sScience and technology as ideology", en Sociology of science, Barry Barnes Ed., Penguin, Harmondsworth.

HAYEK, F. A. (1992), "Discurso inagural de una conferencia en Mont Pelegrin", en Obras completas de F. A. Hayek. Volumen IV : Las visicitudes del liberalismo, Unión Editorial, Madrid.

HENDRIX, P. F., PARMALEE, R.W., CROSSLEY, D.A., COLEMAN, D, ODUM, E.P. y GROFFMAN, P. M. (1986), "Detritus food webs in conventional and no-tillage agroecosystems", en BioScience, 36 (6): 374 380.

HIGHTOWER, J. (1973), Hard tomatoes, hard times, Cambridge Mass, Shenkman.

HOBBELINK, H. (Ed.) (1987), Más allả de la Revolución Verde, Lema S.A., Barcelona.
JANVRY, A. (Ed.) (1981), The agrarian question and reformism in Latin America, The Johns Hopkins University Press, Baltimore.

LANGREO NAVARRO, A. (1988), La Agricultura contractual, COAG, Madrid.

LARSON, O. F. \& E.M. ROGERS (1966), "Rural society in transition: the American setting", en Our changing rural society: perspectives and trends, James H. Coop Ed., lowa State University Press.

LENIN, V.L. (1974), EI desarrolio del capitalismo en Rusia, Ariel, Barcelona.

LONG, N. (1977), Introduction to the sociology of rural development, Tavistock, London.

LOWE, P., MARSDEN, T. Y WHATMORE, S. (1990), Technological change and the rural environement, David Fulton, London.

LOWE, P., MARSDEN, T. y WHATMORE, S. (Eds.) (1993), Cambio tecnológico y medio amblente rural, Ministerio de Agricultura, Madrid.

MALASSIS, L. (1973), Agricultura y proceso de desarrollo, Promoción Culturai/UNESCO, Barcelona.

MARCUSE, H. (1983), Razón y revolución, Alianza, Madrid.

MARTÍNEZ ALIER, J. (1994), De la economía ecológica al ecologismo popular, Icaria, Barcelona.

MORALES, R. y CONTRERAS, A. (1998), RALCO. Modernidad o etnocidio en territorio mapuche, Instituto de Estudios Indigenas, Universidad de la Frontera, Temuco.

MOTTURA, G. y PUGLIESE, E. (1980), "Capitalism in agriculture and capitalistic agriculture: the Italian case", en The rural sociology of the advanced societies, Frederick H. Buttel and Howard Newby Eds., Croom Helm, London.

MUSSOI, E. (1998), Integración entre investigación y extensión agraria en un contexto de descentralización del Estado y sustentabilización de políticas de desarrollo: el caso de Santa Catarina, Brasil, Tesis Doctoral del ISEC, Universidad de Córdoba, España.

NEWBY, H. (1978), "The rural sociology of advanced capitalist societies", en International perspectives in nural sociology, Newby Ed., John. Wiley \& Sons, New York.

NEWBY, H. (1983), Introducción a la sociologia rural, Alianza Editorial, Madrid.

NEWBY, H. (1988), The rural sociology of the advanced societles. Critica! Perspectives, Allanheld Osmund/Croom Helm, Montclair/London.

PALERM, A. (1980), Antropología y manismo, CIS-INAH, México.

PLOEG, J. D. VAN DER (1990) Labor, markets and agricuitura! production, Westview Press, Boulder.

REIJNTJES, C. HAVERKORT, B. Y WATERS-BAYER, A. (1992), Farming for the future, ETC/LEIA and the MacMilian Press L.td., The Netherlands.

SACHS, W. (1992), The development dictionary. A guide to knowledge as power, Zed Books, London. (Existe una edición castellana en Lima: Pratec, 1996 y otra en Cochabamba: CAl, Centro de Aprendizaje Interculturat.)

SCULLION, J., A.R.A. MOHAMMED y G. A. RAMSHAW (1988), "Changes in earthworm populations following cultivation of undisturbed and former opencast coal-mining land", en Agriculture, Ecosystems and Environment, 20: 289-302.

SEVIL.LA GUZMÄN, E. y GINER, S. (1980), "The dernise of the peasant: some reflections on ideological inroads into social theory", en Sociologia Ruralis, Vol. XXX, № : 13-27.

SEVILLA GUZMÁN, E. y GONZẢLEZ DE MOLINA, M. (1990), "Ecosociologia: elementos teóricos para el análisis de la coevolución social y ecológica", en Revista Española de Investigaciones Sociológicas, No $52: 7-45$.

SEVILLA GUZMANN, E. (1991) "Hacia un desarrollo agroecológico desde el campesinado", en Política y Sociedad, № 9: 57-72.

SHANIN T. (1990), Defining Peasants, Basil Blackwelt, Oxford.

SHANIN, T. (Ed.) (1987), Peasant and peasant societes, Basí Blackwell, Oxford.

SHIVA, V. (1991), The violence of the Green Revolution Third Word agriculture. Ecology and politics, Third World Network, Penang.

SOLE, C. (1988), Ensayos de teoria sociológica. Modemización y postmodemidad, Paraninfo, Madrid.

SOROKIN, P. A., ZIMMERMAN, C. C. y GALPIN, C.J. (1965), A systematic source book in rural sociology, Russel, New York.

SWEEZY, P.M. (1982), "Center, periphery, and the crisis of the system", enintroduction to the sociology of developing societies, Alavi and Shanin Eds., The Mac Millan Press, London, pp. 210-217.

TOLEDO, V. (1993), "La racionalidad ecológica de la producción campesina", en Ecologia, campesinado e historia, Sevilla Guzmán y Gonzalez de Molina Eds., La Piqueta, Madrid.

TOURAINE, A. (1969), La sociedad post-industrial, Arie!, Barcelona.

WEBER, M. (1971), The protestant ethic and the spirit of capitalism, Unwin University Books, London. 